\title{
Conservation of ancient full-length open reading frames in vertebrate endogenous retroviruses
}

\author{
Hugo Martins ${ }^{1,2^{*}}$, Palle Villesen ${ }^{1}$ \\ From Frontiers of Retrovirology 2011 \\ Amsterdam, The Netherlands. 3-5 October 2011
}

\begin{abstract}
Background
Endogenous retroviruses (ERVs) are genetic remnants of exogenous retroviral infections that have endured selective processes and made their way into ancestral host genomes. While many of them have deteriorated beyond the ability to code for detectable proteins, some still retain activity or the potential for coding activity [1-3]. A few active ERVs have been coopted into fully functional genes that play important roles in development or disease [1, 2, 4]. New high throughput data revealed that these ERVs are far more common than previously thought and different software packages have been created to search genomes for these structures. In this study, we build on such a tool to look at several vertebrate genomes, search for ERV remnants and identify loci with long, intact open reading frames for the major retroviral genes and dating these loci of interest using the long terminal repeat (LTR) divergence method [5].
\end{abstract}

\section{Materials and methods}

The genomes of twelve vertebrates were acquired from UCSC Genome Browser and analyzed with an in-house method based on the Itrharvest [6] software package, complemented with additional filtering and data retrieval. Candidate ERV loci were then probed for full-length open reading frames, which were classified within one of the three major retroviral genes: gag, pol or env by a BlastX [7] against a retroviral protein database. LTR dating for each ERV locus was done by comparing the genetic divergence between the LTRs.

\section{Results/Conclusions}

Our study reveals the existence of a few conserved full length open reading frames in loci whose LTRs present a similarity lower than $70 \%$ and plenty of open reading

'Bioinformatics Research Centre, Aarhus University, Denmark

Full list of author information is available at the end of the article
Table 1 Number of ERV loci containing large intact open reading frames (at least 1000 uninterrupted nucleotides) for all three major retroviral genes:gag,pol and env,grouped by their locus'LTR divergence percentage

\begin{tabular}{lcccccc}
\hline & $<\mathbf{8 0} \%$ & $\mathbf{8 0 - 8 5 \%}$ & $\mathbf{8 5 - 9 0 \%}$ & $\mathbf{9 0 - 9 5 \%}$ & $>\mathbf{9 5} \%$ & total \\
\hline Human & 0 & 0 & 0 & 1 & 8 & 10 \\
Chimpanzee & 0 & 0 & 0 & 0 & 3 & 3 \\
Orangutan & 0 & 0 & 0 & 1 & 0 & 1 \\
Macaque & 0 & 0 & 0 & 0 & 2 & 2 \\
Dog & 0 & 0 & 0 & 0 & 1 & 1 \\
Mouse & 0 & 0 & 0 & 3 & 169 & 172 \\
Cow & 0 & 0 & 0 & 1 & 7 & 8 \\
Opossum & 0 & 0 & 0 & 7 & 33 & 40 \\
Chicken & 0 & 0 & 0 & 0 & 2 & 2 \\
\hline
\end{tabular}

frames occur across all genomes in loci with LTR similarity below $80 \%$. Current method limitations may cause this number to be an underestimation but nonetheless reveals the existence of old retroviral infections that have, to this date, kept some coding potential. In the studied primate genomes, a select number of loci still retain long to full length open reading frames on all three major genes even on loci with LTR divergence under 95\% (Table 1). Pol genes appear to possess the highest number of conserved ORF and a high number of recent integrations with full conservation has been found in the mouse genome.

\section{Author details \\ ${ }^{1}$ Bioinformatics Research Centre, Aarhus University, Denmark. ${ }^{2} \mathrm{PhD}$ Program in Computational Biology, Instituto Gulbenkian de Ciências, Oeiras, Portugal.}

Published: 3 October 2011

\footnotetext{
References

1. Simpson GR, et al: Endogenous D-type (HERV-K) related sequences are packaged into retroviral particles in the placenta and possess open reading frames for reverse transcriptase. Virology 1996, 222:451-456.
} 
2. Mi S, et al: Syncytin, a captured retroviral envelope protein involved in human placental morphogenesis. Nature 2000, 403:785-789.

3. Takeuchi Y, et al: Host range and interference studies of three classes of pig endogenous retrovirus. J Virol 1998, 72:9986-9991.

4. Nexø BA, et al: The etiology of multiple sclerosis: genetic evidence for the involvement of the human endogenous retrovirus HERV-FC1. PLOS One 2011, 6(2):e16652.

5. SanMiguel $P$, et al: The paleontology of intergene retrotransposons of maize. Nat Genet 1998, 20:43-45.

6. Ellinghaus $D$, et al: LTRharvest, an efficient and flexible software for de novo detection of LTR retrotransposons. BMC Bioinf 2008, 9:18.

7. Altschul SF, et al: Gapped BLAST and PSI-BLAST: a new generation of protein database search programs. Nucleic Acids Res 1997, 25:3389-3402.

doi:10.1186/1742-4690-8-S2-P47

Cite this article as: Martins and Villesen: Conservation of ancient fulllength open reading frames in vertebrate endogenous retroviruses. Retrovirology 2011 8(Suppl 2):P47.

\section{Submit your next manuscript to BioMed Central} and take full advantage of:

- Convenient online submission

- Thorough peer review

- No space constraints or color figure charges

- Immediate publication on acceptance

- Inclusion in PubMed, CAS, Scopus and Google Scholar

- Research which is freely available for redistribution

Submit your manuscript at www.biomedcentral.com/submit 